\title{
Successful Kidney Transplantation in a Patient with Unipapillary Kidney
}

Kosoku A., Uchida J., Shimada H., Kabei K., Nishide S., Iwai T., Kuwabara N., Naganuma T., Maeda K., Kumada N., Takemoto Y., Nakatanti T.

\begin{tabular}{|c|l|}
\hline Citation & Urologia Internationalis, 102(2);243-246 \\
\hline Issue Date & $2019-03$ \\
\hline Type & Journal Article \\
\hline Textversion & Author \\
\hline Rights & $\begin{array}{l}\text { This is the peer-reviewed but unedited manuscript version of the following article: } \\
\text { Urologia Internationalis } 2019 ; 102: 243-246 . \text { The final, published version is available } \\
\text { at https://doi.org/10.1159/000492475 }\end{array}$ \\
\hline DOI & $10.1159 / 000492475$ \\
\hline
\end{tabular}

\author{
Self-Archiving by Author(s) \\ Placed on: Osaka City University
}




\title{
Title:
}

Successful kidney transplantation in a patient with unipapillary kidney

\section{Authors:}

Akihiro Kosoku ${ }^{1}$, Junji Uchida ${ }^{1}$, Hisao Shimada ${ }^{1}, K_{\text {Kazuya Kabei }}{ }^{1}$, Shunji Nishide ${ }^{1}$, Tomoaki Iwai ${ }^{1}$, Nobuyuki Kuwabara ${ }^{1}$, Toshihide Naganuma ${ }^{1}$, Keiko Maeda ${ }^{2}$, Norihiko Kumada $^{3}$, Yoshiaki Takemoto ${ }^{1}$, Tatsuya Nakatani ${ }^{1}$

\author{
Affiliation: \\ ${ }^{1}$ Department of Urology, Osaka City University Graduate School of Medicine \\ ${ }^{2}$ Department of Nursing, Osaka City University Hospital \\ ${ }^{3}$ Department of Urology, Suita Municipal Hospital
}

\section{Short title:}

Transplant for unipapillary kidney

\section{Key words:}

unipapillary kidney, solitary renal calyx, kidney transplantation, renal replacement therapy

\author{
Abbreviations: \\ congenital anomalies of the kidney and urinary tract (CAKUT) \\ end-stage kidney disease (ESKD)
}




\section{Corresponding author:}

Junji Uchida, MD, PhD

Department of Urology, Osaka City University Graduate School of Medicine

1-4-3, Asahi-machi, Abeno-ku, Osaka, 545-8585, Japan

Phone: +81-6-6645-3857, FAX:+81-6-6647-4426

E-mail: m9492120@msic.med.osaka-cu.ac.jp 


\begin{abstract}
:
A unipapillary kidney is a very rare anomaly in humans. In this paper, we report on a case of a 47-year-old woman with end-stage kidney disease (ESKD) due to unipapillary kidney, who had been on hemodialysis for twenty years and successfully received deceased-donor kidney transplantation. The aim of this report is to present a case of a rare unipapillary kidney patient who underwent kidney transplantation without any urological complications. Our results suggest that kidney transplantation may be an effective renal replacement therapy for patients with ESKD due to unipapillary kidney.
\end{abstract}




\section{Introduction}

Congenital anomalies of the kidney and urinary tract (CAKUT) are common and occur at a frequency of 3 to 6 in 1,000 births [1]. However, unipapillary kidney or solitary renal calyx is very rare and frequently associated with other CAKUT [2]. Unipapillary kidney is common in monkeys, rats, rabbits and dogs, while in cows, pigs and humans, multipapillary kidney is common. A unipapillary kidney has an oval-shaped renal pelvis without calyces and well-reserved renal parenchyma. In unipapillary kidney cases, renal function decreases from borderline normal to severe renal failure [3]. We herein report on the first case of a patient with end-stage kidney disease (ESKD) due to unipapillary kidney, who successfully underwent kidney transplantation.

\section{Case report}

Morimoto $\mathrm{S}$ et al. previously reported this case as unipapillary kidney in siblings [4]. The patient was diagnosed with a congenital solitary unipapillary kidney at the age of 17. She had been referred for investigation of proteinuria as a result of a school medical examination. Blood urea nitrogen and serum creatinine were normal levels, but a phenolsulfonphthalein test revealed $11 \%$ excretion of injected dye in 15 minutes and $52 \%$ in 2 hours, showing slightly decreased renal function. Intravenous 
pyelogram revealed only left oval-shaped pelvis with no calyces. Retrograde pyelography demonstrated a right blind-ending narrow ureter up to the level of the fourth limber vertebra and a left bifid ureter which had a blind-ending branch and a branch with an oval-shaped renal pelvis without calyces [4].

Her renal function had gradually decreased due to unipapillary kidney, and she was introduced to hemodialysis at the age of 27 . When she was 47 years old, she was referred to our hospital to receive deceased-donor kidney transplantation.

She underwent a deceased-donor kidney transplant from a 62-year-old male who had been diagnosed as brain dead due to cerebral infarction. She received induction with basiliximab $20 \mathrm{mg}$ intravenously on day 0 and day 4 after transplantation, and an initial immunosuppression regimen of cyclosporine, mycophenolate mofetil and methylprednisolone. The transplant kidney was implanted in the right iliac fossa, with the transplant renal vein anastomosed end-to-end to the external iliac vein and the transplant renal artery anastomosed end-to-side to the external iliac artery.

Because she had received dialysis for about twenty years and the period of anuria had been long, her bladder was contracted at transplantation due to long-term disuse. Before transplantation, we verified bladder capacity by infusion of saline into bladder. Bladder capacity was only $50 \mathrm{ml}$, measured as mount of saline infused in the 
bladder. It was necessary to avoid uretero-ureteral anastomosis because of possible dysfunction of the native ureter, and the transplant ureter was anastomosed to the contracted bladder using the Lich-Gregoir method. After kidney transplantation, the volume of urine output was low, and hemodialysis was necessary for one week, which was consistent with acute tubular necrosis. She withdrew hemodialysis on post-transplant 14 days and the serum creatinine levels gradually decreased (Table 1). At 10-year follow-up, the patient had no major complications including rejection and was in good clinical condition with mild renal insufficiency (serum creatinine 2.14 $\mathrm{mg} / \mathrm{dL}$ ). Voiding cystourethrography showed absence of vesicoureteral reflux in the native and transplant ureter after kidney transplantation. Magnetic resonance imaging revealed the normal transplant kidney (Fig 1(a)) and hypoplastic native kidney that has only oval-shaped pelvis with no calyces (Fig 1(b)).

\section{Discussion}

Unipapillary kidney was first reported in 1960 by Neal A et al [5]. To our knowledge, only 21 cases (25 kidneys) of unipapillary kidneys have been described so far [2][3][6]. They were associated with CAKUT such as hypoplasia or agenesis of the contralateral kidney, megaureter, ectopic ureter, bladder agenesis and posterior urethral valve. The renal function of all patients decreased from borderline normal to severe 
renal failure. A previous report showed that a patient with unipapillary kidney received peritoneal dialysis as renal replacement therapy [2]. This may be the first demonstration that a patient with ESKD due to unipapillary kidney, who might have other abnormalities including abnormal function of the urinary tract, underwent successful kidney transplantation as renal replacement therapy.

Embryologically, arising from the Wolffian duct and invading the adjacent metanephric mesenchyme of the ureteric bud, the development of the human kidney is initiated at five weeks of human fetal gestation. The ureteric bud divides dichotomously, making generations of branches. The first 3 to 5 generations form the renal pelvis and major calyces, and the next 3 to 5 generations form the minor calyces. At ten weeks, the pelvis and major calyces are dilated with differentiation of nephrons. At thirteen to fourteen weeks, the minor calyces and papillae become similar to those in a mature kidney. A unipapillary kidney is assumed to be the result of cessation of branching after the first 3 to 5 generations, which create the pelvis. Nephrons attach to fewer collecting tubules, which then drain directly into the pelvis. [7]

Some of the patients reported were led to a diagnosis of unipapillary kidney by the investigation of recurrent urinary tract infection complicated with CAKUT. Demos et al. showed a unipapillary kidney patient whose posterior urethral valve was incised 
endoscopically [8]. Kaneto et al. described a 4-month-old girl accompanied by bilateral single ectopic ureter and hypoplastic bladder, who underwent bilateral ureterocutaneostomy and bladder reconstruction using an ileocecal segment and urethroplasty using the hypoplastic bladder one year later [2]. They also reported on a 10-month-old boy with left normal kidney and right unipapillary kidney with megaureter who underwent right ureteroneocystostomy. These previous reports described surgical treatments for CAKUT complicated by unipapillary kidney to preserve renal function, although there is no established surgical treatment for unipapillary kidney (Figure 2).

In this report, we demonstrated that kidney transplantation may be an effective renal replacement therapy for patients with ESKD due to unipapillary kidney. Before kidney transplantation for these patients, the bladder function and vesicoureteral reflux should be evaluated, and it may be important to determine the need of surgical treatment for CAKUT which can threaten transplant renal function as well as consider where to anastomose the transplant ureter. The present case had a unipapillary kidney and agenesis of the contralateral kidney with a blind-ending narrow ureter. Because the bladder was expected to contract due to long-term disuse and a detailed examination was difficult to perform, this evaluation was not conducted in our patient. 
In conclusion, we experienced a successful kidney transplant case with unipapillary kidney without urological complications. Kidney transplantation may be an effective renal replacement therapy for patients with ESKD due to unipapillary kidney.

\section{Conflict of interest}

The authors declare no conflicts of interest.

\section{Ethics}

The patient gave informed consent to publish images and details in the study.

\section{References}

1: Yosypiv IV: Congenital anomalies of the kidney and urinary tract: a genetic disorder? Int J Nephrol. 2012; DOI: 10.1155/2012/909083.

2: Kaneto H, Metoki R, Fukuzaki A, Kuji S, Ishikawa H, Orikasa S: Unicalyceal kidney associated with ureteral anomalies. Eur Urol. 1997;32:328-331.

3: Smith SJ, Cass AS, Aliabadi H, Ambani N, Gleich P, Winter RB: Unipapillary kidney: a case report and literature review. Urol Radiol. 1984;6:43-47.

4: Morimoto S, Sangen H, Takamatsu M, Kitagawa M, Fujinaga T, Kitamura S, Ohkawa T.: Solitary calix in siblings. J Urol. 1979; 122:690-691

5: Neal A, Murphy L: "Uni-Papillary Kidney" An unusual developmental abnormality of the kidney. J Coll Radiol Aust. 1960;4:81-83. 
6: Jolly BB, Jolly M: Unipapillary kidney: a case report. Urol Int. 1995;54:175-176.

7: Toppercer A. Unipapillary human kidney associated with urinary and genital abnormalities. Urology. 1980; 16: 194-196.

8: Demos TC, Malone A, Schuster GA: Unicaliceal kidney associated with posterior urethral valves. J Urol. 1983;129:1034-1035. 
Table 1. Post-transplant serum electrolyte and urea profiles

\begin{tabular}{l|cccc} 
& \multicolumn{4}{|c}{ Time post-transplant } \\
& 2 weeks & 2 months & 3 months & 6 months \\
\hline BUN (mg/dL) & 22 & 27 & 38 & 29 \\
$\mathrm{Cr}(\mathrm{mg} / \mathrm{dL})$ & 4.1 & 1.75 & 1.99 & 1.75 \\
$\mathrm{Na}(\mathrm{mEq} / \mathrm{L})$ & 139 & 142 & 140 & 142 \\
$\mathrm{~K}(\mathrm{mEq} / \mathrm{L})$ & 3.5 & 4.9 & 5.5 & 4.8 \\
$\mathrm{Cl}(\mathrm{mEq} / \mathrm{L})$ & 102 & 108 & 114 & 107
\end{tabular}




\section{Figure legend:}

Figure 1.

Magnetic resonance imaging shows (a) the normal transplant kidney without

hydronephrosis (b) the hypoplastic native kidney that has only oval-shaped pelvis with no calyces. 


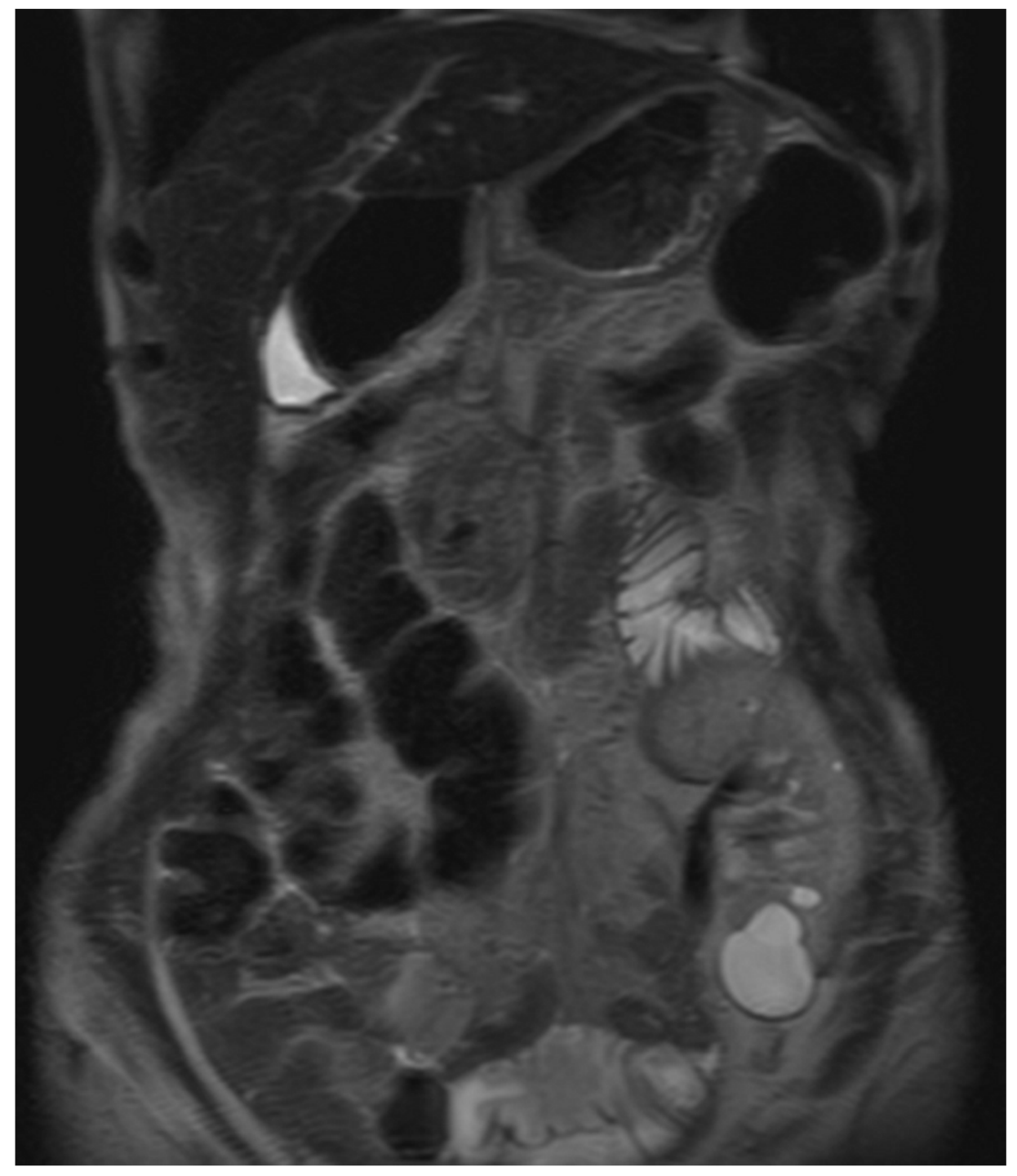

(a)

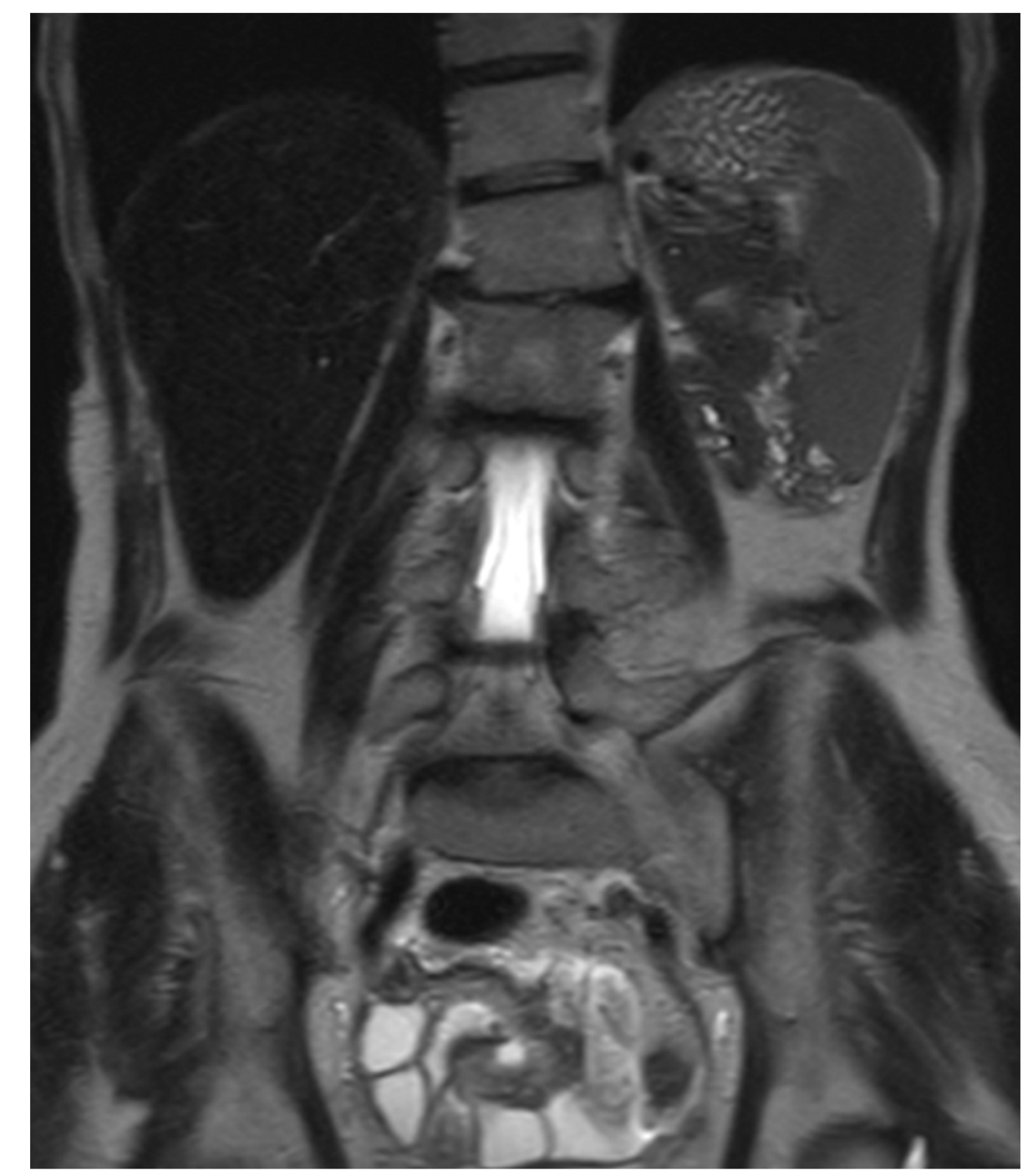

(b) 
Figure 2.

Therapeutic management of patients with unipapillary kidney. CAKUT; congenital anomalies of the kidney and urinary tract.

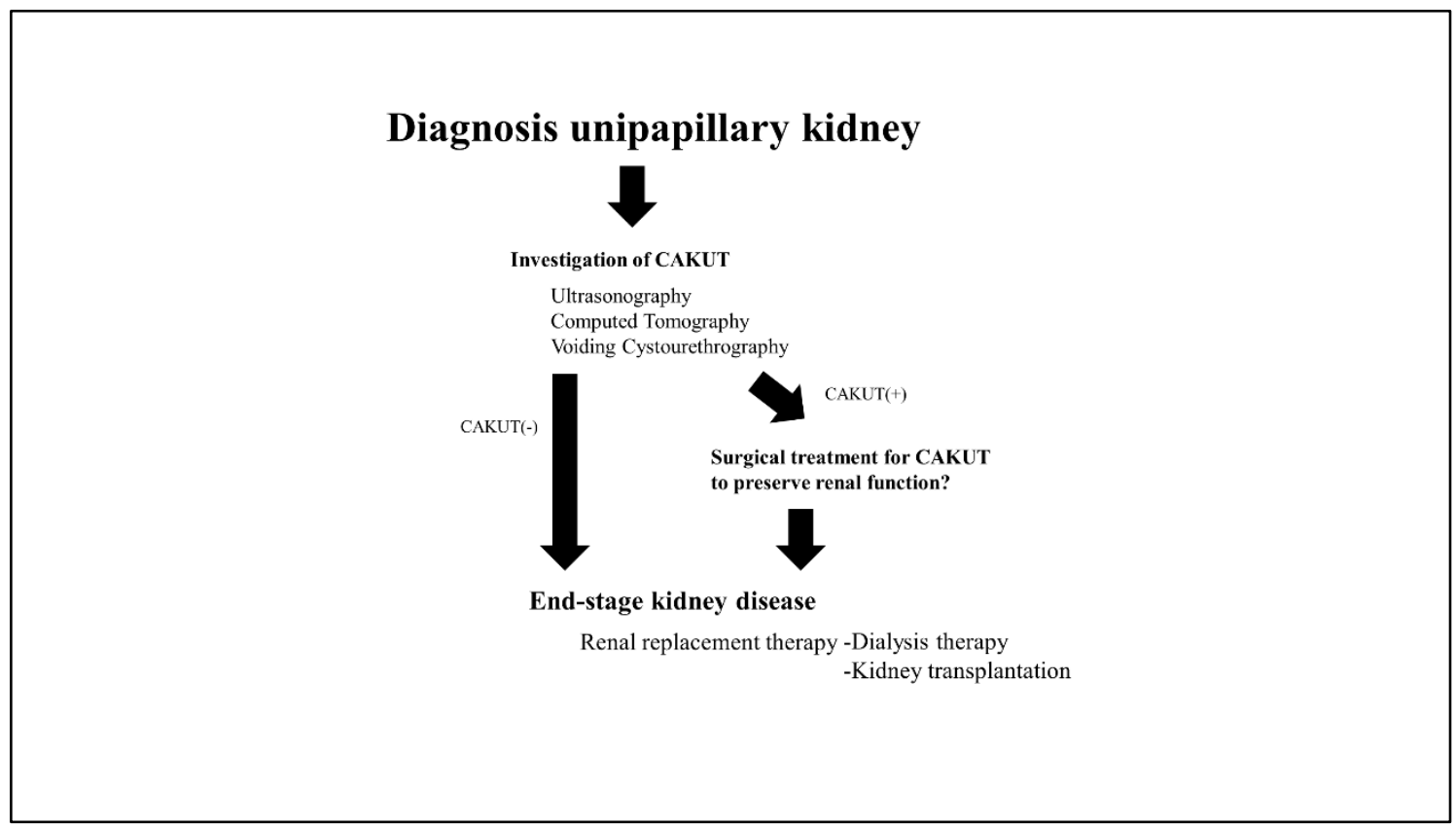

